\title{
The Medical Research Council and the development of clinical science:
}

\author{
'The soul of wit may become the very body of untruth'. Aldous Huxley \\ D R JAMES
}

Ever since the establishment of its predecessor, the Medical Research Committee, the MRC has actively sought to foster the development of clinical research within the United Kingdom. In 1917 the Committee had urged the Minister of Education to establish clinical units within teaching hospitals where both research and teaching could be conducted to their mutual benefit. In the preceding year the Committee had appointed Dr Thomas (later Sir Thomas) Lewis to its staff and were able to arrange for him to have beds and facilities at the Cardiographic Department of University College Hospital. This proved to be an inspired appointment and Lewis was to play a major role in the development of clinical research until the end of the Second World War. His group at University College Hospital was known as the Department of Clinical Research and was, in effect, the first of the Council's Research Units; a form of support which has stood the test of time in the wider spheres of medical research as well as in clinical sciences. The influence of the Department on the development of clinical science both in this country and internationally was of major proportions. Among the many distinguished clinicians who worked there may be mentioned Sir Alan Drury (later to become Director of the Lister Institute), Sir George Pickering, Sir Edward Wayne, Sir Edward Pochin, and Dr J R Squire.

In the early 1930s the Council established two further clinical research units. The first was in the field of clinical neurology, where Dr E A Carmichael was appointed Director of a Unit at the National Hospital for Nervous Diseases. The second was at Guy`s Hospital, where Lewis’s protegé Dr R T Grant was appointed Director. One further clinical unit, the Unit for Clinical Research in Surgery, was set up before the Second World War. This was established in Edinburgh and was initially led by $\mathrm{Mr} \mathrm{W} \mathrm{C}$ Wilson. These early developments all exemplified the characteristics that have been central to the MRC support of research - first the identification of the outstanding individual to lead a research endeavour and second, the recognition of the scientific opportunities - that is, the problems that are amenable to research. The flourishing of clinical research during this period had its seeds in the advances in physiology and biochemistry that had occurred in the latter half of the 19th and early part of the 20th centuries. A further opportunity was presented by the increasingly sophisticated statistical methods that could be applied to the evaluation of the effectiveness of medical interventions. The Council's own statistical staff were to play a leading role in the development of these methods and the contributions of Bradford Hill, Doll and Cochrane are all well known. Although the Council had been involved in carrying out clinical trials as early as 1922, the major developments in this area followed the establishment of a Therapeutic Trials Committee in 1931. The Committee played a large part in the evaluation of new treatments, in particular calciferol for rickets, sulphanilamide for septicaemia, and digoxin for auricular fibrillation. After the Second World War the Council was to take the lead in the evaluation of novel drugs for the treatment of tuberculosis. The MRC Tuberculosis Unit, under the direction of Dr P D'Arcy Hart, carried out an exemplary series of randomised controlled clinical trials of treatments for the various clinical presentations of this infection. The evaluation of chemotherapy for TB has continued with MRC support to the present day with current trials being carried out in the Far East. With time the controlled clinical trial came to be applied in many areas of medicine. Its application to the treatment of cancer has been instrumental in leading to substantial improvements in prognosis for a number of different forms of neoplastic disease. In 1958 the Council established a committee for the evaluation of different methods of cancer therapy under the Chairmanship of Sir Brian Windeyer. This Committee, which subsequently became the Cancer Trials Committee, set up working parties to evaluate therapies for specific cancers and substantial progress has been made, particularly in the treatment of Hodgkins lymphoma, some forms of leukaemia, and testicular cancer.

The introduction of the National Health Service in 1948 was to have a profound influence on the 
development of clinical research in the post war era. The National Health Service Act made explicit provision for Government to conduct research and to assist others to do so. This authority for conducting research was exercised on the one hand through the establishment of a Clinical Research Board within the Medical Research Council, to which the Chief Medical Officers of the Health Departments were appointed as assessors, and on the other through the arrangements for locally organised research administered by the Regional Hospital Boards. The detailed arrangements for the organisation of clinical research were published in a memorandum from the Ministry of Health and the Department of Health for Scotland in 1957. That memorandum stated explicitly that 'the Secretary of State regards clinical research as an essential and inseparable aspect of the medical services provided in hospitals'. The policy of integrating clinical services with clinical research reached its apogée in the establishment of the Clinical Research Centre alongside a new District General Hospital at Northwick Park in Harrow. It was the intention from the outset that the Clinical Research Centre/ Northwick Park Hospital should fulfil a very different role from that of the Postgraduate Medical School/ Hammersmith Hospital and other teaching centres in London. Hammersmith Hospital had built up a reputation as a tertiary referral centre and was providing excellent training at postgraduate level. It had established itself as a leading centre for clinical research. The work of the Clinical Research Centre on the other hand was to be orientated towards the study of those diseases which formed the bulk of the work of a District General Hospital. It was also intended that it should develop a national role in clinical research.

In 1978, at a time of vigorous developments in clinical science, Christopher Booth was appointed Director to the still quite young Clinical Research Centre (CRC). In this role he was responsible for developing the administrative structure and the academic atmosphere of the CRC and at the same time promoting harmonious and constructive relationships with the Harrow Health Authority. Behind all these efforts there was an unswerving devotion to the cause of clinical science. Dr Booth made a major contribution by encouraging the development of the new biological and genetic approaches to disease in all the relevant programmes at the $\mathrm{CRC}$ rather than confining these to a single unit. $^{\prime}$

While the arguments for the establishment of the Clinical Research Centre were undoubtedly cogent at the time other important influences, initially only dimly perceived by a few far sighted individuals, gradually came to pervade medical research. Among these influences the most important was the increasing scope for applying the techniques of the modern biological sciences, and in particular molecular biology, to the study of clinical disease. The MRC had made pioneering contributions to molecular biology, particularly through the work of its Laboratory of Molecular Biology in Cambridge. The application of the knowledge derived from work in that Laboratory to clinical research was initially slow. The first disease to be characterised at a molecular level was a form of sickle cell disease where the abnormality was shown to be the result of a single amino acid substitution in the haemoglobin protein. More rapid advances had to await the development of the methodologies for gene cloning and for mapping DNA through the use of restriction enzymes. The Council had supported the research of Professor (later Sir) David Weatherall on the molecular basis of haemoglobinopathies since the late 1960)s. In 1980 he became the Honorary Director of the MRC's first unit in molecular medicine, the Molecular Haematology Unit in Oxford. More recently the MRC, with financial assistance from the Wolfson Foundation, the Imperial Cancer Research Fund and the E P Abraham Trust, have supported the foundation of an Institute of Molecular Medicine in Oxford, which brings together the Molecular Haematology Unit and a number of other groups applying the techniques of modern biological sciences to a range of clinical diseases.

No account of the MRC's role in the advancement of clinical science would be complete without reference to its support for research training. As early as 1936 the Council established six postgraduate studentships for training in research methods that could be applied to clinical medicine and experimental pathology. At the same time four senior fellowships were established for individuals who had already gained some experience of research. Both of these types of award were to come to an end during the Second World War, but in 1950 the Council established its Clinical Research Fellowship Scheme; a form of support that was continued well into the 1970s. It has been a cardinal principle of the MRC's support for clinical research training that there should be opportunities for training at each successive stage of the clinical career ladder, and that research training should offer the possibility, when the trainees have both the ability and the inclination, of career positions in research. At the present time, support for clinicians, who have completed their house appointments and wish to undertake research training, is provided by MRC Training Fellowships. Of late these awards have been particularly successful with fellowships being awarded to over 30 well qualified clinicians per annum. The Council's Senior 
Clinical Fellowships provide support for six years for those who have already begun to make distinctive contributions to clinical research. In addition to clinical appointments in its own establishments, the MRC also provides careers for clinical research workers through the MRC Clinical Research Professorships and Readerships. Since these forms of support were introduced in 1979 four Clinical Research Professors have been appointed. The first was Professor John Newsom-Davies, who was subsequently to become Professor of Clinical Neurology in Oxford. The other awards were to Professor Andrew McMichael (Clinical Immunology, Oxford), Professor David Baird (Obstetrics and Gynaecology, Edinburgh) and Professor Stephen Holgate (Medicine, Southampton). In recognition of the increasing importance of basic science in clinical research the Council has initiated within the last year a scheme of clinician scientist fellowships which provide support for seven years; the first three of which should be spent in a basic science department.

How will the Council's policies develop in the future? The evolution of clinical research within the UK suggests that a number of key elements are essential for its successful development. First, that education, training, and research should proceed in parallel within the same institution. Second, that clinical research must be closely integrated with the relevant basic sciences, and that the latter need to be present in significant strength for them to provide a wellspring of innovation and not simply the application of existing techniques to clinical problems. Third, there must continue to be opportunities for the best clinical research workers to devote their energies full time to research with no more than the necessary minimum distraction of clinical service, teaching and administrative responsibilities. The Council's proposals for the establishment of a New National Centre for postgraduate medical education, training and research should ensure that all these objectives are satisfied within that new institution. It is recognised, however, that the New National Centre should form only a part, although a key one. of the Council's future strategy for clinical research. Through its clinical research initiative, the MRC will be seeking to selectively strengthen the clinical research base at other institutions so these can play a complementary role to the New National Centre in the future of clinical science in the UK. The clinical research initiative is being pursued at a time when major changes in the structure of the Health Service are being proposed by Government. The earlier introduction of the National Health Service provided both a challenge and an opportunity for clinical research. The new proposals also clearly present a challenge, and the Council will be striving to ensure that, if they are put into effect, the position of clinical research will be not only safeguarded but that there will also be opportunities for it to develop to meet the needs of the future.

I am indebted in the preparation of this brief article to the writings of the late Sir Landsborough Thompson' and Chris Booth. ${ }^{3}$ The painstaking documentation of the former and the scholarship and perceptiveness of the latter are acknowledged with admiration.

\section{Medical Research Council, \\ 20 Park Crescent, \\ London WIN $4 A L$}

\section{References}

1 Tyrell DAJ. Retirement of Sir Christopher Booth. MRC News 1989; no. 42: 41

2 Landsborough Thompson A. Half a century of medical research. Vols. 1 and 2. London: HMSO, 1973 and 1975.

3 Booth CC. Clinical research and the MRC. Q J Med 1986; series 59: $435-47$. 